\title{
Is the Income Elasticity of the Willingness to Pay for Pollution Control Constant?
}

\author{
Edward B. Barbier ${ }^{1}$ • Mikołaj Czajkowski ${ }^{2}$. \\ Nick Hanley ${ }^{3}$
}

Accepted: 31 May 2016 / Published online: 14 June 2016

(C) The Author(s) 2016. This article is published with open access at Springerlink.com

\begin{abstract}
How willingness to pay for environmental quality changes as incomes rise is a central question in several areas of environmental economics. This paper explores both theoretically and empirically whether or not the willingness to pay (WTP) for pollution control varies with income. Our model indicates that the income elasticity of the marginal WTP for pollution reduction is only constant under very restrictive conditions. Our empirical analysis tests the null hypothesis that the elasticity of the WTP for pollution control with respect to income is constant, employing a multi-country contingent valuation study of eutrophication reduction in the Baltic Sea. Our findings reject this hypothesis, and estimate an income elasticity of the WTP for eutrophication control of $0.1-0.2$ for low-income respondents and $0.6-0.7$ for high-income respondents. Thus, our empirical results suggest that the elasticity is not constant but is always less than one. This has implications for how benefits transfer exercises, and for theoretical explanations of the environmental Kuznets curve.
\end{abstract}

Keywords Baltic Sea · Benefits transfer - Environmental Kuznets curve · Eutrophication · Income elasticity of willingness to pay $\cdot$ Non-market valuation

JEL Classification Q51 - Q53 · Q56

\section{Introduction}

Since the seminal study by Kriström and Riera (1996), economists have debated whether and how the willingness to pay (WTP) for environmental improvement varies with respect to

Mikołaj Czajkowski

miq@wne.uw.edu.pl

1 Department of Economics and Finance, University of Wyoming, Laramie, WY, USA

2 Department of Economics, University of Warsaw, Warsaw, Poland

3 Department of Geography and Sustainable Development, University of St. Andrews, St. Andrews, Scotland 
income, and what the likely magnitude of that income elasticity might be. There is evidence from consumer expenditure surveys that environmental quality could be a luxury good, implying that the income elasticity of demand is higher than one (Ghalwash 2008). In contrast, studies that directly estimate the income elasticity of WTP for environmental improvement find that this elasticity is typically less than one (Kriström and Riera 1996; Ready et al. 2002; Hökby and Söderqvist 2003; Jacobsen and Hanley 2009; Czajkowski and Ščasný 2010). Others have shown that the theoretical relationship between the elasticity of demand and the income elasticity of WTP is not straightforward for environmental public goods, and that knowledge of the one does not necessarily provide information on the other (Flores and Carson 1997; Ebert 2003).

Whether the elasticity of the WTP for environmental improvement with respect to income is constant is yet to be resolved. There is a growing theoretical literature suggesting that this parameter is unlikely to be constant (Flores and Carson 1997; Ebert 2003; Hökby and Söderqvist 2003). Similarly, some theoretical explanations of the environmental Kuznets curve (EKC) are consistent with the marginal WTP for reducing pollution varying with income (McConnell 1997; Stokey 1998; Andreoni and Levinson 2001; Israel and Levinson 2004). In contrast, recommended guidance principles for benefits transfer are often based on the assumption that the income elasticity of these WTP values is constant (Pearce 2006; Ready and Navrud 2006; Czajkowski and Ščasný 2010; Lindhjem and Navrud 2015).

The purpose of this paper is to explore both theoretically and empirically whether or not the WTP for pollution control varies with income. A theoretical explanation is presented of how the income elasticity of WTP for more of an environmental good-or less of an environmental bad-varies with income. We then undertake an empirical investigation of whether or not the income elasticity is constant, based on a large multi-country dataset of individual WTP survey responses for environmental improvements in the Baltic Sea.

Following Andreoni and Levinson (2001), Israel and Levinson (2004), McConnell (1997) and Stokey (1998), our theoretical model demonstrates the conditions under which the elasticity of the marginal WTP for reducing pollution with respect to income is likely to be constant. However, in contrast to these earlier models in which environmental quality is controlled in a social planner's problem, the model developed here is based on a representative agent's decision whether or not to contribute some portion of their income to pollution reduction. Since our derivation of the income elasticity is based on preferences, it enables a comparison with theoretical explorations in the environmental valuation literature that distinguish the income elasticity of WTP from the demand for environmental quality with respect to income (Flores and Carson 1997; Ebert 2003; Hökby and Söderqvist 2003). Our model indicates that the income elasticity of the marginal WTP for pollution reduction is only constant under very restrictive conditions, and moreover, confirms that a constant elasticity is not necessary for generating an environmental Kuznets curve relationship between pollution levels and income per capita.

Although the main objective of our theoretical model is to show conceptually what might influence the income elasticity of the marginal WTP for pollution reduction, and how this elasticity might vary across people, actually determining whether this elasticity is constant is primarily an empirical issue. Consequently, the aim of our empirical analysis is to test the null hypothesis that the elasticity of the WTP for pollution control with respect to income is constant. To do this, we make use of a large multi-country dataset from a contingent valuation study of the benefits of meeting nutrient reduction targets for the Baltic Sea (Ahtiainen et al. 2014). The survey was aimed at estimating the WTP for reducing eutrophication in the Baltic Sea, with respondents drawn from 9 littoral countries-Denmark, Estonia, Finland, Germany, Latvia, Lithuania, Poland, Russia and Sweden. Due to the large differences in respondents' 
income levels between and within these countries, the dataset provides a unique opportunity to examine the income elasticity of WTP for reducing eutrophication across a very wide range of household income levels-from less than 500 to over 5000 euros (EUR) per month. We employ the Box-Cox model to test our null hypothesis, which is rejected. We find that the income elasticity of the WTP for eutrophication control is increasing and concave, and that it behaves similarly irrespectively of model specification. It takes values of $0.1-0.2$ for low-income respondents and reaches $0.6-0.7$ for the highest income levels observed in our dataset. This result is consistent with previous findings (Ready et al. 2002; Czajkowski and Ščasný 2010).

The outline of our paper is as follows. The next section develops our theoretical model of the WTP for pollution reduction, which we use to derive the conditions under which the income elasticity of this WTP is constant. Next, we discuss the implications of this model for deriving an environmental Kuznets curve relationship between pollution levels and income per capita and for non-marginal pollution reductions. The subsequent sections of the paper develop our Box-Cox regression model for testing the null hypothesis that the elasticity of the marginal WTP for pollution control with respect to income is constant, and apply this model to our case study of eutrophication control in Baltic Sea countries. We conclude by discussing our theoretical and empirical results, and their implications for future research.

\section{Theoretical Model}

Assume that there are $N$ individuals in an economy, who may be willing to pay for a specific improvement in environmental quality, such as reducing the water pollution associated with eutrophication of a nearby coastal area. Eutrophication is disliked because it accelerates growth of algae in water bodies, diminishes enjoyment of seaside recreation and disrupts aquatic ecosystems. The water pollution causing eutrophication consists of nutrient emissions, which are directly linked to the total levels of production and consumption in the economy. Assuming a feasible technology for abating these emissions, individuals may be willing to forego some of their income that would otherwise be spent on consumption in order to contribute to overall pollution abatement.

Thus the utility function of a representative agent in the economy is

$$
U=U(c, P), \quad U_{c}>0, \quad U_{c c}<0, \quad U_{P}<0, \quad U_{P P}<0,
$$

where $c$ is per capita consumption and $P$ is the overall water pollution level associated with eutrophication. Let $y$ denote the individual's given level of per capita income. The choice is to allocate a share. $\omega \in[0, \bar{\omega}]$. of this income to pollution control, with the remainder spent on consumption. However, there is a minimal level of consumption that ensures an upper limit $\bar{\omega}$ on the individual's allocation of income to pollution abatement, i.e., $c=(1-\bar{\omega}) y=\bar{c}$.

If $\alpha(N \omega y)$ is the reduction in pollution through all individuals' expenditures on pollution control, then overall emissions generated in the economy is

$$
P=[c N-\alpha(\omega y N)]=(1-\omega) y-\alpha(\omega y), \quad N=1,
$$

where normalizing the number of individuals maintains the focus on the representative agent's decision (e.g., $P$ can now be thought of as per capita pollution levels). The abatement technology is governed by

$$
\alpha^{\prime}(\omega y)>0, \quad \alpha(0)=0, \quad \alpha^{\prime}(0)=0, \quad \alpha(\bar{\omega} y)=\bar{\alpha}, \quad \alpha^{\prime}(\bar{\omega} y)=\beta<\infty .
$$


For a given income level, pollution abatement is an increasing function of expenditure allocated to pollution control. Abatement cannot occur if no money is allocated to reducing pollution, abatement is finite if the maximum amount is allocated to control, and the rate of increase in pollution abatement at the upper limit on control is bounded above by $\beta$.

The representative agent's problem is

$$
\max _{\omega \in[0, \bar{\omega}]} U((1-\omega) y,(1-\omega) y-\alpha(\omega y)) .
$$

For the given level of income $y$, the optimal allocation share for reducing pollution $\omega^{*}$ satisfies

$$
\begin{aligned}
& -U_{C}-U_{P}\left(1+\alpha^{\prime}\right) \leq 0, \quad \omega \geq 0 \\
& -U_{C}-U_{P}\left(1+\alpha^{\prime}\right) \geq 0, \quad \omega \leq \bar{\omega}
\end{aligned}
$$

For the corner solution $\omega=0$, the marginal benefit of pollution abatement $-U_{P}\left(1+\alpha^{\prime}\right)$ is less than the cost $U_{C} y$, and thus the individual will not contribute any income to emission reduction. All of the agent's income will be devoted to consumption, and thus pollution will be at its maximum $P=c=y$. For the other corner solution $\omega=\bar{\omega}$, the marginal benefit of pollution abatement exceeds the marginal cost, and the individual will allocate the maximum amount of income to pollution reduction. As this corner solution is not important for what follows, for simplicity it will be assumed that $\omega>\bar{\omega}$.

The marginal WTP for pollution reduction $w_{p}$ is therefore defined by the marginal rate of substitution between less pollution and more consumption $-U_{P} / U_{c}$ and is governed by the following condition

$$
w_{p}=-\frac{U_{P}}{U_{c}} \leq \frac{1}{1+\alpha^{\prime}}, \quad \omega \geq 0 .
$$

In the case of the corner solution, the WTP is equal only to the marginal rate of substitution between less pollution and consumption. In the case of the interior solution, the marginal rate of substitution must also equal $1 / 1+\alpha^{\prime}$, the opportunity cost of less pollution in terms of foregone consumption.

For the corner solution case, when the representative agent allocates no income to pollution reduction, $\omega=0$. It follows from (2) and (6) that $P=c=y$ and $w_{P}=-U_{P}(y) / U_{C}(y)$. Consequently,

$$
\frac{\partial w_{P}}{\partial y}=\frac{U_{c c} U_{P}-U_{P P} U_{c}}{\left[U_{c}\right]^{2}}>0, \quad \varepsilon_{P} \equiv \frac{\partial w_{P}}{\partial y} \cdot \frac{y}{w_{P}}=\frac{U_{c c} U_{P}-U_{P P} U_{c}}{-U_{c} U_{P}} y>0 .
$$

The marginal WTP for pollution control increases with income, and the elasticity of $w_{p}$ with respect to income is also positive. Because the terms in the denominator of $\varepsilon_{P}$ in (7) are a function of per capita income, this elasticity is not constant.

For the interior optimum, changes in $w_{P}=-U_{P} / U_{c}$ correspond to changes in the opportunity cost of reduced pollution $1 / 1+\alpha^{\prime}$. By examining how changes in $y$ affect the right-hand side of (6), we can infer how marginal WTP for pollution reduction also responds to changes in income. It follows that

$$
\frac{\partial w_{P}}{\partial y}=\frac{-\alpha^{\prime \prime} \omega}{\left[1+\alpha^{\prime}\right]^{2}}, \quad \varepsilon_{P} \equiv \frac{\partial w_{P}}{\partial y} \cdot \frac{y}{w_{P}}=\frac{-\alpha^{\prime \prime}}{1+\alpha^{\prime}} \omega y .
$$

As Eq. (8) indicates, how the marginal WTP for reduced pollution changes with income depends on the curvature of the abatement technology function $\alpha(\omega y)$ as governed by (3). If this technology is increasing and convex, and thus $\alpha^{\prime \prime}>0$, then as income increases $w_{p}$ falls. However, if abatement technology is increasing and concave so that $\alpha^{\prime \prime}<0$, then $w_{p}$ rises 
as income increases. There is no change in $w_{p}$ if abatement increases linearly with pollution reduction expenditure $\left(\alpha^{\prime \prime}=0\right)$. Similarly, the income elasticity of the marginal WTP for pollution reduction also varies with abatement technology, i.e., $\varepsilon_{P} \gtreqless 0$ if $\alpha^{\prime \prime} \lesseqgtr 0$. Unless abatement technology is linear so that $\varepsilon_{P}=0$, for different per capita income levels, the income elasticity of WTP is not constant.

Finally, as (7) indicates, even if the individual allocates no income to pollution control, the agent's marginal WTP for pollution reduction rises with per capita income. If income arises above some threshold level $\hat{y}$, the interior solution is reached. It follows that the conditions for optimal abatement, pollution levels and marginal WTP for pollution reduction can be restated as

$$
\begin{gathered}
\alpha\left(\omega^{*} y\right)=0, \quad P=c=y, \quad w_{P}=\frac{-U_{P}}{U_{c}}, \quad y \leq \hat{y} \\
\alpha\left(\omega^{*} y\right)>0, \quad P=\left(1-\omega^{*}\right) y-\alpha\left(\omega^{*} y\right), \quad w_{P}=\frac{1}{1+\alpha^{\prime}\left(\omega^{*} y\right)}, \quad y>\hat{y} .
\end{gathered}
$$

As per capita income rises to $\hat{y}$, pollution increases by the same amount. It must reach its maximum at $\hat{y}$, because for income beyond this threshold, emissions declines at the rate $\partial P / \partial y=-\omega^{*}\left(1+\alpha^{\prime}\right)<0$.

\section{Discussion}

Figure 1 summarizes the key results. The upper diagram shows the change in the marginal WTP for pollution reduction as per capita income increases, and the bottom diagram indicates the resulting pollution-income relationship. Because the top figure is drawn in $c-P$ space, the marginal rate of substitution relationship in (6) is transformed to $U_{c} /-U_{P} \geq 1+\alpha^{\prime}$. The corresponding indifference curves are depicted as solid lines, and the increasing and convex production possibility frontiers for different pollution-consumption combinations are the dotted lines. Although the latter frontiers are drawn through the origin, for a given level of income, there is always a minimal level of pollution given by $\bar{P}=\bar{c}-\alpha(\bar{\omega} y)$.

Assume that the initial level of per capita income $y_{0}$ is well below the threshold level $\hat{y}$. This corresponds to a corner solution at point A, where the marginal WTP for pollution reduction is defined by the marginal rate of substitution between less pollution and consumption (see condition (6) above). As income increases, $w_{P}$ rises although pollution continues to increase as $P=c=y$. At point $\mathrm{B}$, income attains the threshold level, and although still a corner solution, pollution reaches its peak $\hat{P}$. If income increases above the threshold level, the marginal WTP for pollution reduction and its elasticity with respect to income depends on the opportunity cost of pollution reduction, which in turn is dictated by the abatement technology. Point $\mathrm{C}$ represents one such interior optimum. Figure 1 indicates the case where the abatement technology is increasing but concave with respect to pollution control expenditures, i.e., $\alpha^{\prime \prime}(\omega y)<0$. The income elasticity of the marginal WTP for pollution reduction is positive, but as income increases, pollution declines more slowly with income (i.e., the slope of the pollution-income relationship beyond $\hat{y}$ becomes flatter).

These results confirm, as Flores and Carson (1997) and Ebert (2003) have shown, that the demand for environmental quality with respect to income does not indicate the actual income elasticity for the WTP for pollution reduction. Similarly, a constant elasticity is not necessary for an environmental Kuznets curve relationship between pollution levels and income per capita (McConnell 1997; Israel and Levinson 2004). Although in the corner solution there is no demand for reduced pollution and emissions increase exactly with income 
Fig. 1 Marginal willingness to pay and pollution as a function of income

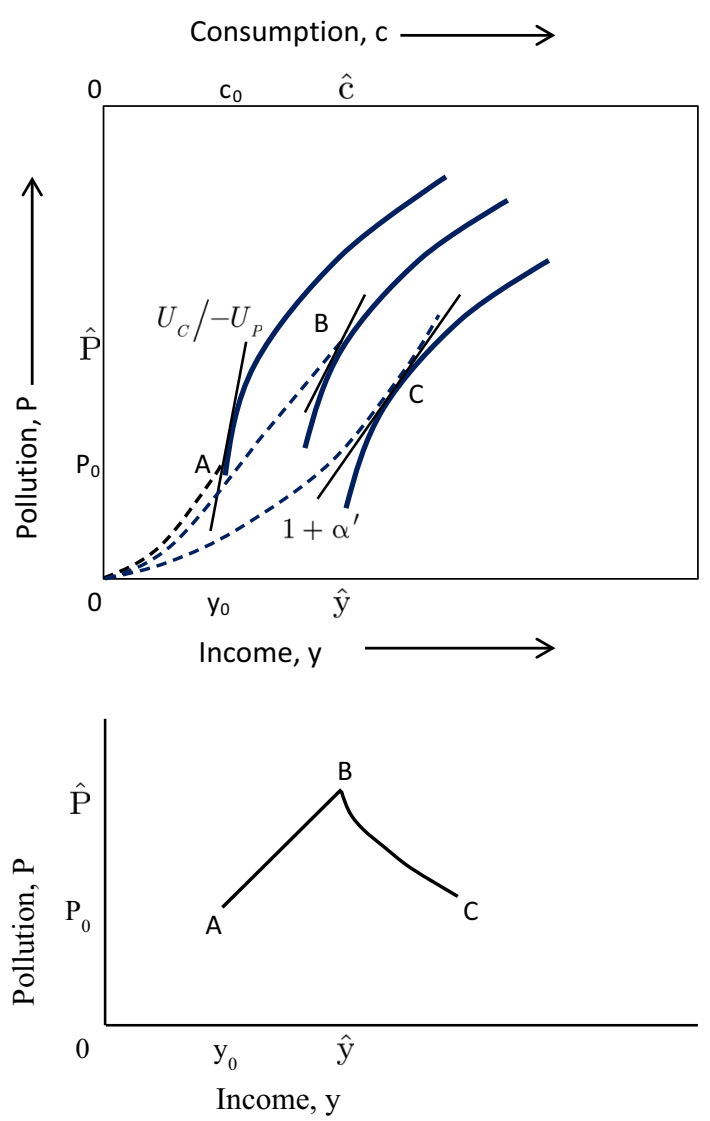

and consumption, $P=c=y$, the WTP income elasticity is positive and increasing with income. Above the threshold $\hat{y}$, pollution always declines with increased income, but the income elasticity $\varepsilon_{P}$ could be increasing, decreasing or constant.

Although the derived pollution-income relationship in this model is similar to that in Stokey (1998), the conditions leading to this relationship differ. Stokey (1998) assumes that pollution increases with income at low per capita income levels in an economy because it is too poor to modify the "dirtiest" emissions technology. Here, the key determinant is whether or not the average individual is willing to allocate some income to pollution reduction expenditures. Our theoretical result is thus based on preferences. If the representative agent is not willing to spend any income on control, then pollution increases with income. Once some income is allocated to reduce emissions, the abatement technology influences not only how pollution declines with income but also the sign and magnitude of the income elasticity of the WTP for pollution control. This role of abatement technology in affecting any pollution-income relationship is consistent with Andreoni and Levinson (2001), who show that the returns to scale in pollution control is key to an environmental-Kuznets curve for pollution.

Note also that, if the elasticity of the WTP for a marginal reduction in pollution with respect to income is not constant, then the income elasticity of the WTP for a non-marginal pollution reduction is also unlikely to be constant. For example, the WTP by an individual for a non-marginal reduction in water pollution from $P_{0}$ to $P_{1}$ is by definition 


$$
W(P)=-\int_{P_{0}}^{P_{1}} w_{p}(y) d p, \quad P_{1}<P_{0},
$$

which is the area under the marginal WTP curve bounded by the pollution levels $P_{0}$ to $P_{1}$. It follows that the effects of a change in income on the WTP for a non-marginal reduction in pollution is $\frac{\partial W(P)}{\partial y}=-\int_{P_{0}}^{P_{1}} \frac{\partial w_{p}}{\partial y} d p$ and the corresponding income elasticity is

$$
\varepsilon_{W}=\frac{\partial W(P)}{\partial y} \cdot \frac{y}{W(P)}=\frac{y \int_{P_{0}}^{P_{1}} \frac{\partial w_{p}}{\partial y} d p}{\int_{P_{0}}^{P_{1}} w_{p}(y) d p} .
$$

Unless $\partial w_{P} / \partial y=0$, the income elasticity of the WTP for a non-marginal pollution reduction, $\varepsilon_{W}$, is not constant. As already shown above, $\partial w_{P} / \partial y>0$ for the corner solution and is only equal to zero under for the interior optimum if the abatement technology is linear (i.e., $\alpha^{\prime \prime}=0$ ).

To summarize, the results derived from our theoretical model indicate that the elasticity of the marginal WTP of individuals for pollution reduction is only constant under some very restrictive conditions. Nor is a constant elasticity necessary to derive an environmental Kuznets relationship between pollution and income. Determining how this elasticity varies with income, and its magnitude at different income levels, is therefore an empirical issue that requires further investigation.

\section{Empirical Strategy}

Our empirical analysis explores the relationship between consumers' WTP for improving environmental quality (i.e., reducing pollution) and income. We investigate this relationship econometrically using the Box-Cox model extended for use with multi-variate data (Box and Cox 1964; Andrews et al. 1971). In particular, we adopt the following functional form of the Box-Cox model, which has become an accepted standard in econometric studies in cases where specification of the functional relationship between some variables of interest cannot be based on a priori economic rationale (Sakia 1992):

$$
y_{i}^{\left(\lambda_{0}\right)}=\beta_{0}+\sum_{k=1}^{K} x_{k i}^{\left(\lambda_{k}\right)} \beta_{k}+\varepsilon_{i} .
$$

Note that, in the above specification, the dependent and each of the explanatory variables can be transformed with a different parameter. These transformations incorporate a wide range of functional forms, nesting linear $(\lambda=1)$, logarithmic $(\lambda=0)$, unit root and many others, and as such allow for a great flexibility. As a result, estimations based on (13) have been extensively used for uncovering a wide range of non-linear relationships in economics. ${ }^{1}$

In what follows we apply this approach for modelling the income elasticity of the WTP for controlling pollution. There are two main reasons for this-firstly, it incorporates a wide range of functional forms which allows us to investigate the a priori unknown form of nonlinearity of the relationship (and correct for the natural skewedness in the data). Secondly,

1 For example, recent empirical applications include the functional form of cost functions (Berbeka et al. 2012), modelling price changes (Milon et al. 1984; Mishili et al. 2011; Karaman and Yavuz 2014), portfolio choice (Garlappi and Skoulakis 2011), the economic effects of invasive species (Horsch and Lewis 2009), elasticities of demand and supply (Bessler et al. 1984; Czajkowski and Ščasný 2010), and various health economics applications Manning (2013). 
since it includes logarithmic transformation as a special case, it provides a convenient way to test the restriction that the transformation parameters of WTP (dependent variable) for pollution control and income (one of the explanatory variables) are both equal to zero, which is equivalent of the $\log -\log$ relationship and results in the income elasticity of WTP being constant. $^{2}$

To take into account the possibility that the maximum likelihood estimation of the BoxCox transformed regression model may not be robust to heteroskedascity (Zarembka 1974), we allow for multiplicative variance heterogeneity of the following form

$$
\varepsilon_{i} \sim f\left(0, \sigma^{2} \exp \left(\mathbf{z}_{i} \boldsymbol{\gamma}\right)^{2}\right),
$$

where $\mathbf{z}$ is a vector of explanatory variables of variance and $\boldsymbol{\gamma}$-a vector of the associated parameters estimated simultaneously with linear and transformation parameters of the model. ${ }^{3}$

\section{Case Study}

We empirically explore the relationship between WTP for pollution control and income using a large dataset from a contingent valuation study of the benefits of meeting nutrient reduction targets for the Baltic Sea. The survey was aimed at estimating respondents' WTP for reducing eutrophication (one of the most prominent threats to the Baltic Sea) and its environmental effects on water clarity, blue-green algal blooms, sea grass beds, and fish species composition (Ahtiainen et al. 2014).

The study was conducted in 9 littoral countries of the Baltic Sea: Denmark, Estonia, Finland, Germany, Latvia, Lithuania, Poland, Russia and Sweden, with the adult population in these countries totaling over 230 million people. Due to the large differences in the income levels between and within these countries, the dataset provides an opportunity to examine income elasticity of WTP for reducing eutrophication across a very wide range of income levels-from less than 500 to over 5000 EUR per month.

The study used a payment card as a WTP elicitation format (Rowe et al. 1996). The bid vectors used in these cards were country specific, based on the distribution of WTP observed in pilot studies. However, the payment cards were otherwise constructed using the same bid design methodology (Roach et al. 2002). In what follows, we use the mid-point of each respondent's selected interval as an estimate of his or her individual maximum WTP.

The contingent scenario and the survey were designed following state-of-the-art standards for contingent valuation studies (Bateman et al. 2004; Champ et al. 2004; Carson and Hanemann 2005; Dillman et al. 2014). Identical questionnaires, translated into national languages, were used to collect the data. See Ahtiainen et al. (2014)) for the details regarding the study, the results and their policy relevance.

The survey was designed in 2010-2011 and implemented in October-December 2011. The primary data collection method was Computer Assisted Web Interviews (CAWI), Computer Assisted Personal Interviews (CAPI) were, however, used in the countries where the internet coverage was low, thus not warranting representativeness of a web-based sample (Latvia, Lithuania and Russia; Poland implemented both methods simultaneously). Both CAPI and

\footnotetext{
2 To test this hypothesis we use asymptotic distribution of the likelihood ratio, which have been shown to have good power properties in this case (Doksum and Wong 1983).

3 The estimation package allowing for independent Box-Cox transformations of all model variables, multiplicative heteroskedascity and imposing restrictions was written in Matlab and is available from http://github. com/czaj/BoxCox under Creative Commons BY 4.0 license.
} 
CAWI were conducted by professional survey companies. Samples were randomly drawn and stratified to represent national population data on, gender, age and regional location.

In total, 10,564 surveys were collected across the nine countries of which 10,396 were complete enough to be used in this analysis. Table 1 presents socio-demographic characteristics of the survey sample versus general population in each country. The samples exhibited reasonable properties in terms of representativeness, with possibly larger households, lower net income and higher education levels compared to the official statistics.

Ahtiainen et al. (2014) use the same data to calculate the benefits of meeting nutrient reduction targets for the Baltic Sea. In addition, however, they also make an effort to investigate the differences between country-specific income elasticity of WTP. To this end, they estimate a model imposing a constant income elasticity of WTP, and use the nine country-specific estimates to infer the relationship between the estimated (constant) income elasticity of WTP and the income level in each country, finding no significant relationship. In what follows, we provide a substantially extended analysis, by estimating a Box-Cox regression models which allow for non-constant income elasticity of WTP. The relationship between income elasticity of WTP and the income level is then investigated on an individual respondent level, rather than on a country level.

\section{Results}

We apply the Box-Cox regression model (13) to the data collected in the empirical Baltic Sea study described above. Since our primary interest is in estimating the relationship of respondents' WTP for eutrophication reduction and income levels, we estimated the model employing the following specification

$$
W T P_{i}^{\left(\lambda_{0}\right)}=\mathbf{x}_{i} \boldsymbol{\gamma}+\text { income }_{i}^{\left(\lambda_{1}\right)} \beta_{\text {income }}+\varepsilon_{i},
$$

where $\left(\lambda_{0}\right)$ and $\left(\lambda_{1}\right)$ refer to separate Box-Cox transformation parameters. In order to account for likely differences between the countries' average WTP levels we used a fixed-effect type of treatment where the $\mathbf{x}_{i}$ vector includes dummy variables for each of the countries. We tested if our results are robust across several specifications, such as including additional respondent specific controls in $\mathbf{x}_{i}$ (sex, age, education level and household size), allowing for heteroskedascity (the error term variance to be country-specific, as specified in (14)) or both.

The results of these modelling approaches are presented in Table $2 .{ }^{4}$ Country-specific fixed effects were a substantial and statistically significant improvement to our models, and in addition, some of the country-specific constants were statistically different from each other, indicating differences in mean WTP levels. Respondents' net income was also a highly significant explanatory variable of WTP for eutrophication reduction. Most of the respondent-specific control variables were also significant: male respondents were willing to pay consistently less than others, and respondents who were better educated and who lived in higher-income households were willing to pay more. The explanatory variables of the error term variance (not reported) were all highly significant and substantially improved the model fit. These results are consistent across all model specifications.

The Box-Cox transformation parameters associated with the variables WTP and income in (15) are both significantly different from zero. This is an indication that, at least in the

4 Both WTP and income levels were converted to EUR using Purchasing Power Parity (PPP) corrected exchange rates. 


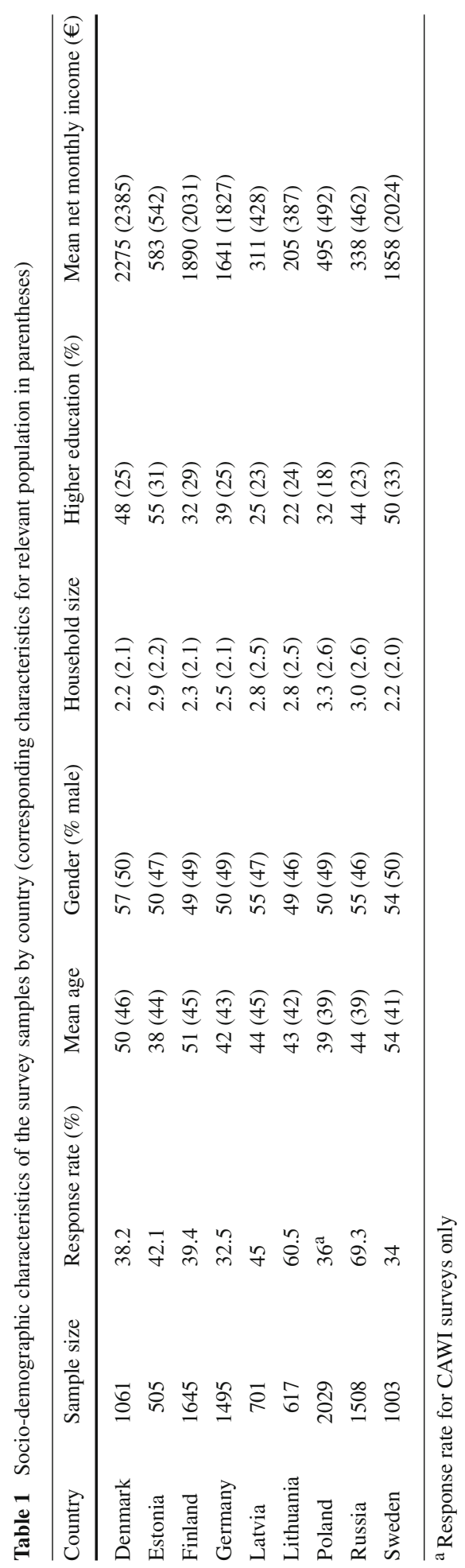




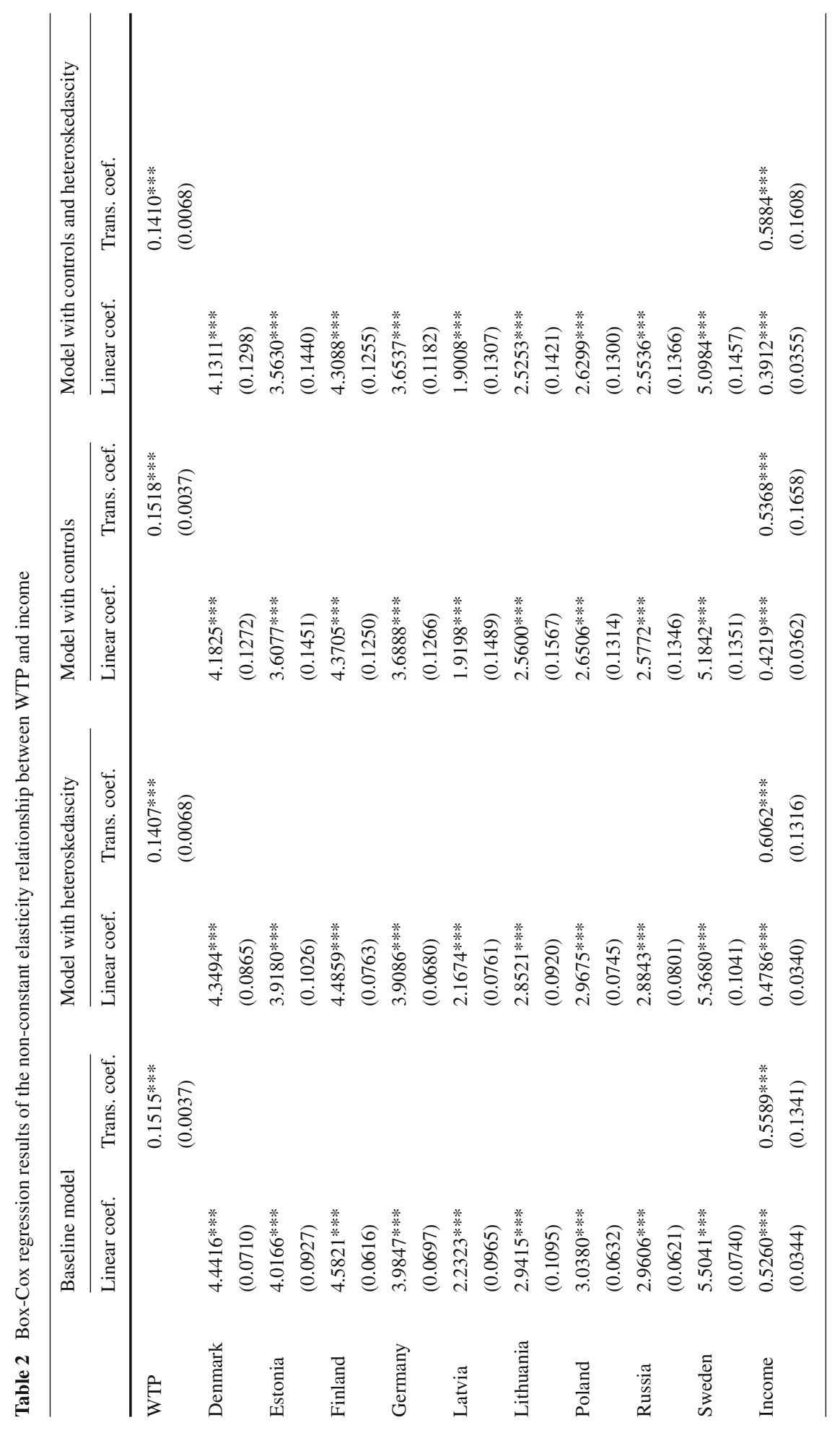




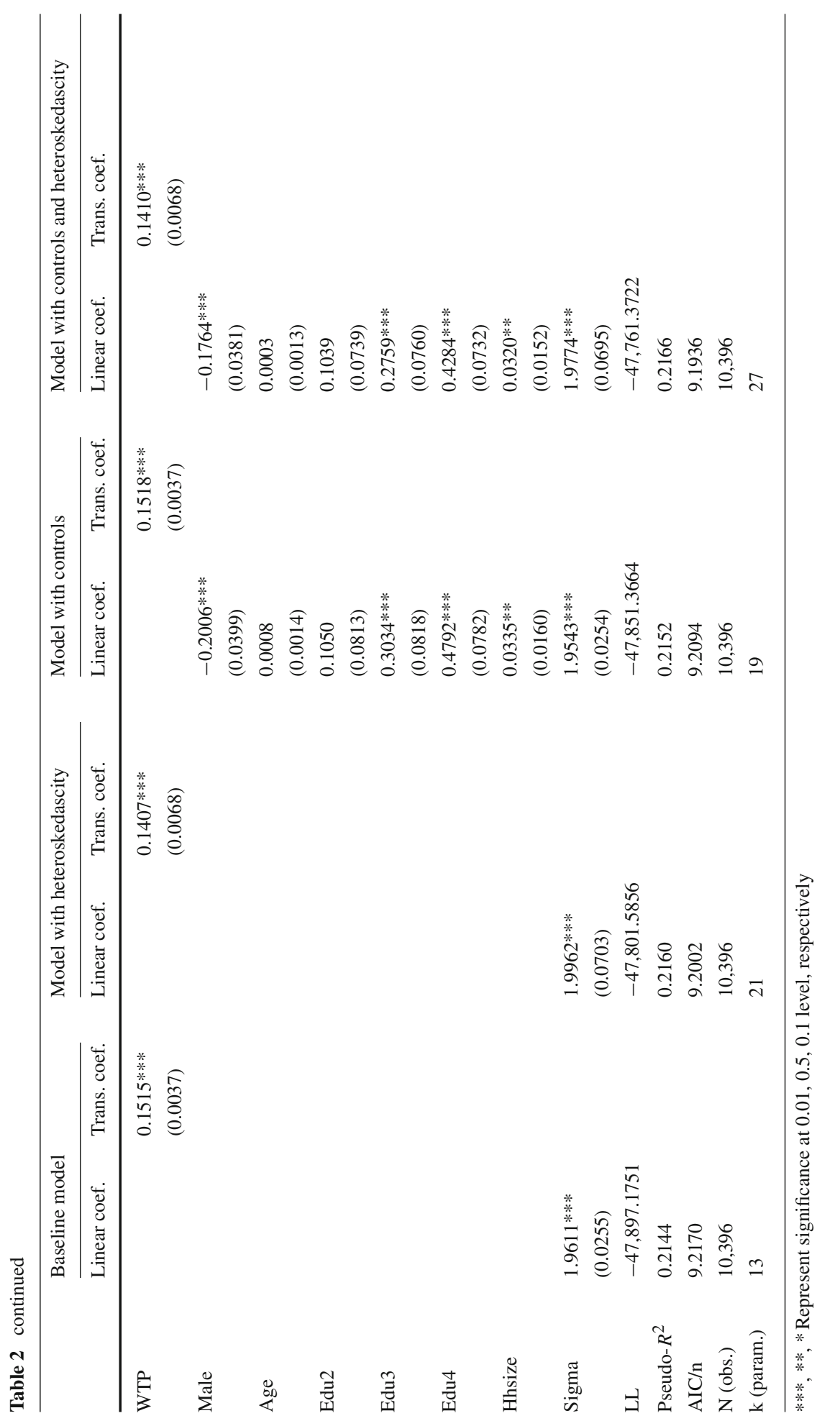


case of our dataset, a lognormal transformation of WTP and income is not superior to other functional forms, and hence the elasticity of WTP for pollution control with respect to income is not constant. Thus, it appears that our null hypothesis can be rejected.

To formally test this hypothesis, in Table 3 we present the results of the models in which both Box-Cox transformation parameters were constrained to zero, resulting in the log-log relationship between WTP for eutrophication reduction and income. The estimated (constant) income elasticity is in the range of $0.23-0.29$ (depending on the model specification), which is in line with the evidence from studies which used a similar specification (e.g., Kriström and Riera 1996; Ready et al. 2002; Hökby and Söderqvist 2003; Jacobsen and Hanley 2009). We note, however, that this specification is outperformed by a more flexible functional form, and therefore, the restriction is unjustified. Since the two models are nested, we are able to test this using the likelihood ratio test the results of which are presented in Table 4 . The critical value for the test statistic (Chi-squared with $2^{\circ}$ of freedom) is 5.99 and therefore, we can easily reject the restrictions, implying that the income elasticity of WTP is not constant for our Baltic Sea dataset.

Finally, to provide an insight into the dynamics of the changes of the income elasticity of WTP for eutrophication reduction, we calculate its values for different levels of income. Following from our Box-Cox regression model specification (15), the elasticity is

$$
\psi=\frac{\frac{d W T P}{W T P}}{\frac{\text { dincome }}{\text { income }}}=\frac{\partial \log (\text { WTP })}{\partial \log (\text { income })}=\frac{\beta_{\text {income }} \text { income } \lambda^{\lambda_{1}}}{\lambda_{0}\left(\mathbf{x} \boldsymbol{\gamma}+\beta_{\text {income }} \frac{\text { income }^{\lambda_{1}}-1}{\lambda_{1}}\right)+1} .
$$

Figures 2, 3, 4 and 5 present the resulting elasticity estimates for different levels of income observed in our data with the accompanying $95 \%$ confidence intervals ${ }^{5}$. We find that the income elasticity is increasing and concave, and that it behaves similarly irrespectively of model specification. It takes values of $0.1-0.2$ for low-income respondents and reaches $0.6-$ 0.7 for the highest income levels observed in our dataset. This result is consistent with previous findings in that the elasticity is less than one (Kriström and Riera 1996; Hökby and Söderqvist 2003; Jacobsen and Hanley 2009; Lindhjem and Tuan 2012), and varies with income (Ready et al. 2002; Czajkowski and Ščasný 2010).

\section{Conclusion}

Our analysis demonstrates both theoretically and empirically that the income elasticity of the WTP for environmental improvement is unlikely to be constant. We confirm that one cannot infer the income elasticity for WTP for pollution reduction from the demand for environmental quality with respect to income, and vice versa (Flores and Carson 1997; Ebert 2003). In addition, a constant elasticity is not necessary for an environmental Kuznets curve relationship between pollution levels and income per capita (McConnell 1997; Israel and Levinson 2004). In fact, we show that the elasticity of the marginal WTP of for pollution reduction is only constant under very restrictive conditions.

Overall, these results should finally put to rest the "folklore myth" that an environmental Kuznets curve for pollution control implies that the environment is a luxury good (Kriström

\footnotetext{
5 The confidence intervals were simulated numerically (Krinsky and Robb 1986). We used $10^{6}$ draws from multivariate normal distribution given by the vector of parameters and the associated variance-covariance matrix of each model and for each set of parameters drawn in this way calculated the resulting elasticity (for each income level). The lower and upper bound of the $95 \%$ confidence interval is approximated with the 0.025 and 0.975 quantiles of the resulting empirical distribution.
} 


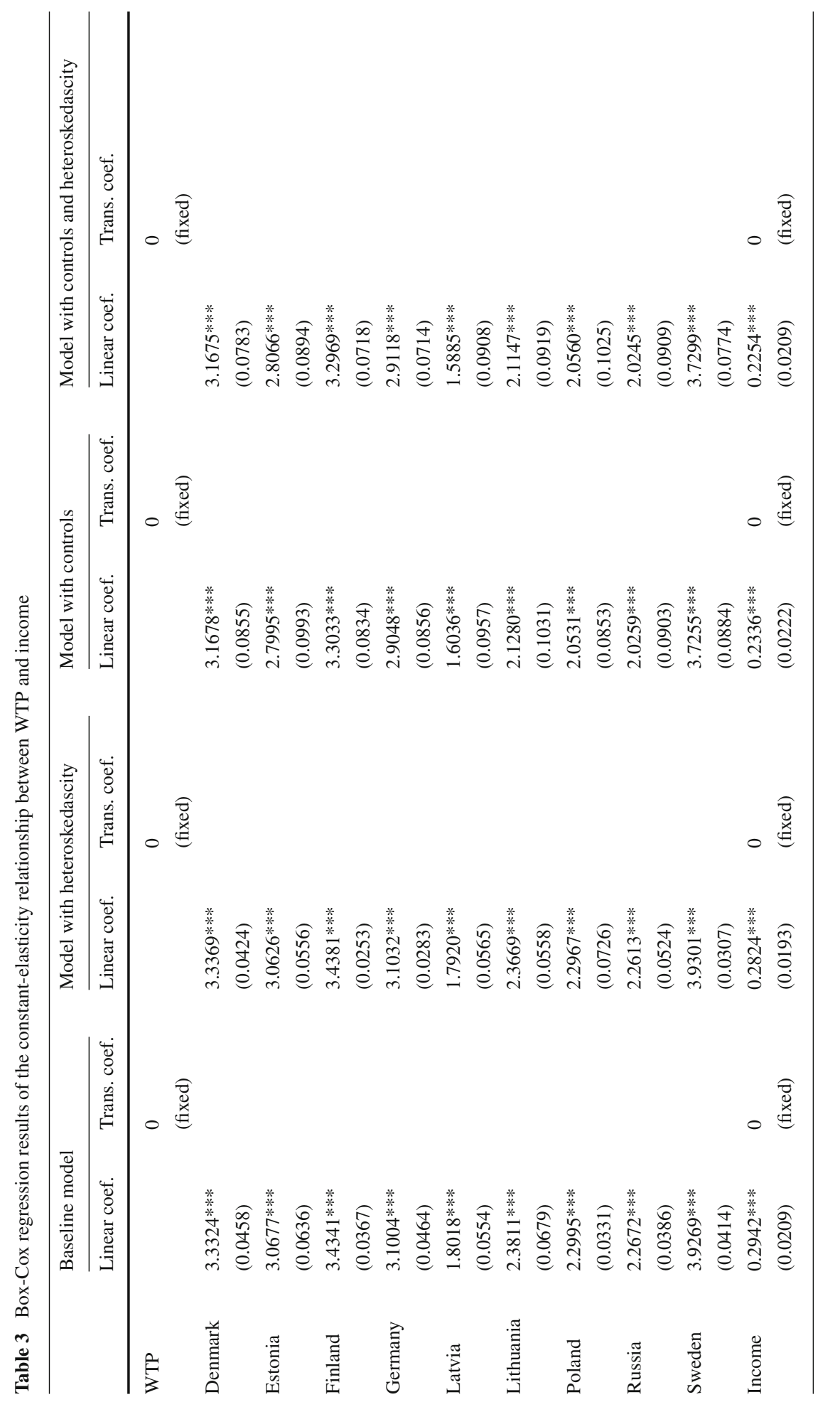




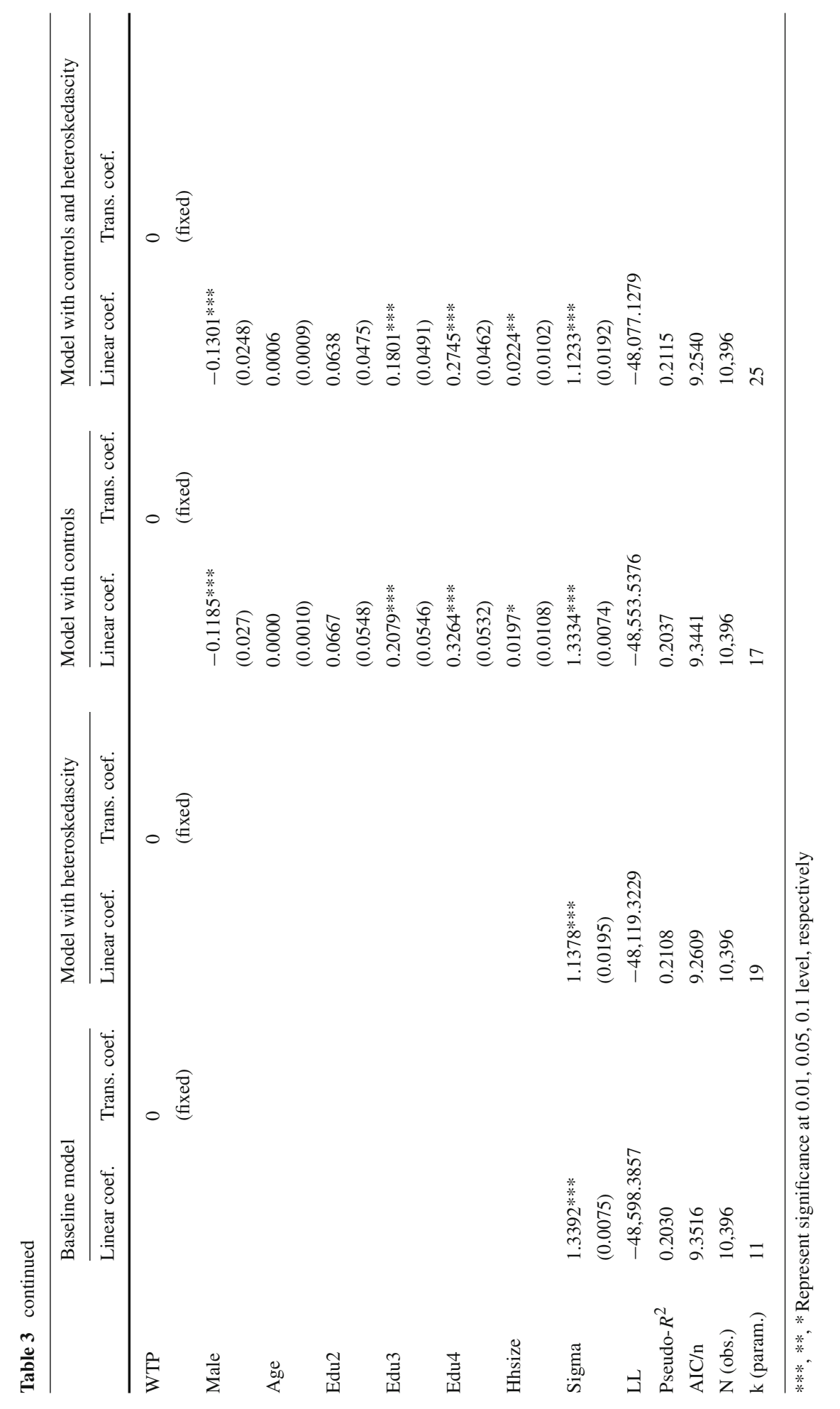


Table 4 Likelihood ratio test results of the non-linear versus constant income elasticity of WTP

\begin{tabular}{llll} 
Baseline model & $\begin{array}{l}\text { Model with } \\
\text { heteroskedascity }\end{array}$ & $\begin{array}{l}\text { Model with } \\
\text { controls }\end{array}$ & $\begin{array}{l}\text { Model with } \\
\text { controls and } \\
\text { heteroskedascity }\end{array}$ \\
\hline$-47,897.1751$ & $-47,801.5856$ & $-47,851.3664$ & $-47,761.3722$ \\
$-48,598.3857$ & $-48,119.3229$ & $-48,553.5376$ & $-48,077.1279$ \\
1402.4212 & 635.4745 & 1404.3424 & 631.5114 \\
$<0.0001$ & $<0.0001$ & $<0.0001$ & $<0.0001$ \\
\hline
\end{tabular}

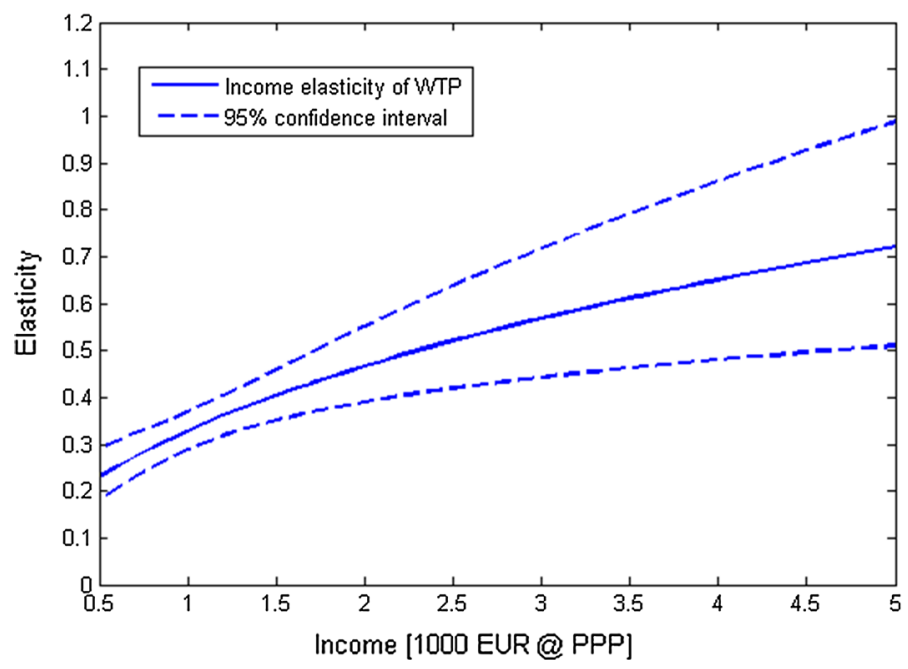

Fig. 2 Income elasticity of WTP-baseline model

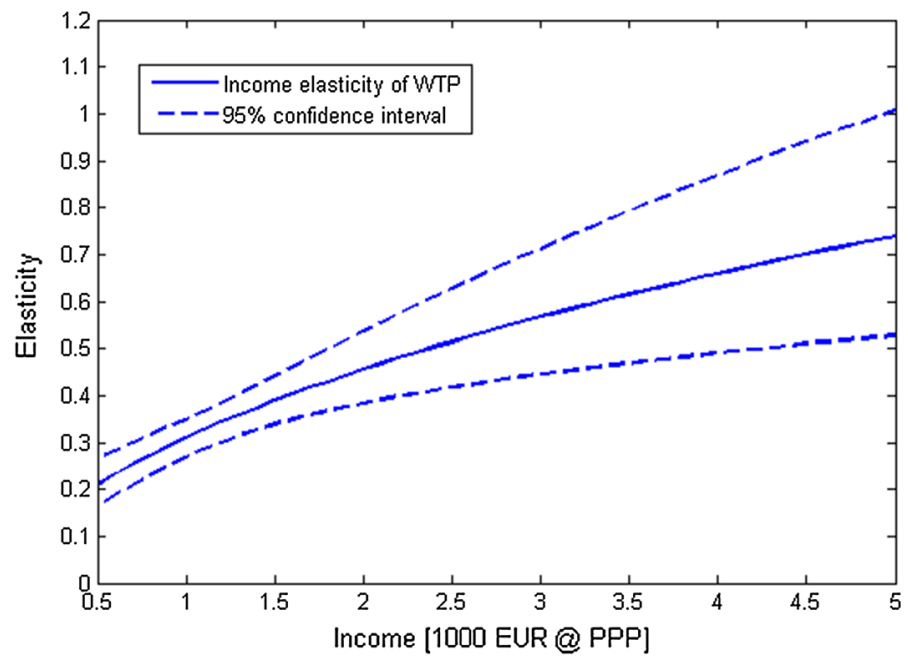

Fig. 3 Income elasticity of WTP-baseline model with heteroskedascity 


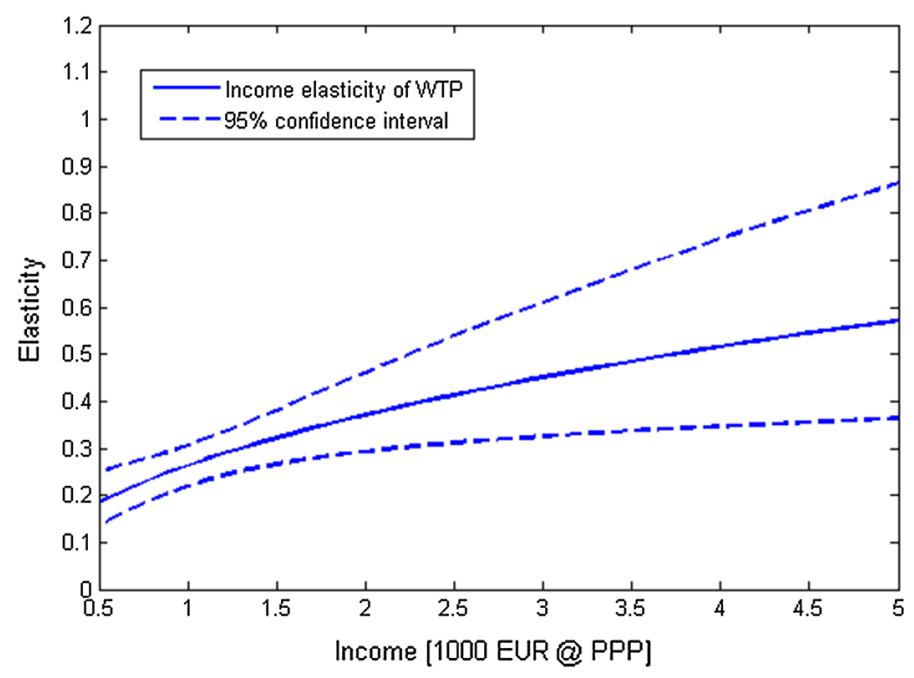

Fig. 4 Income elasticity of WTP-baseline model with controls

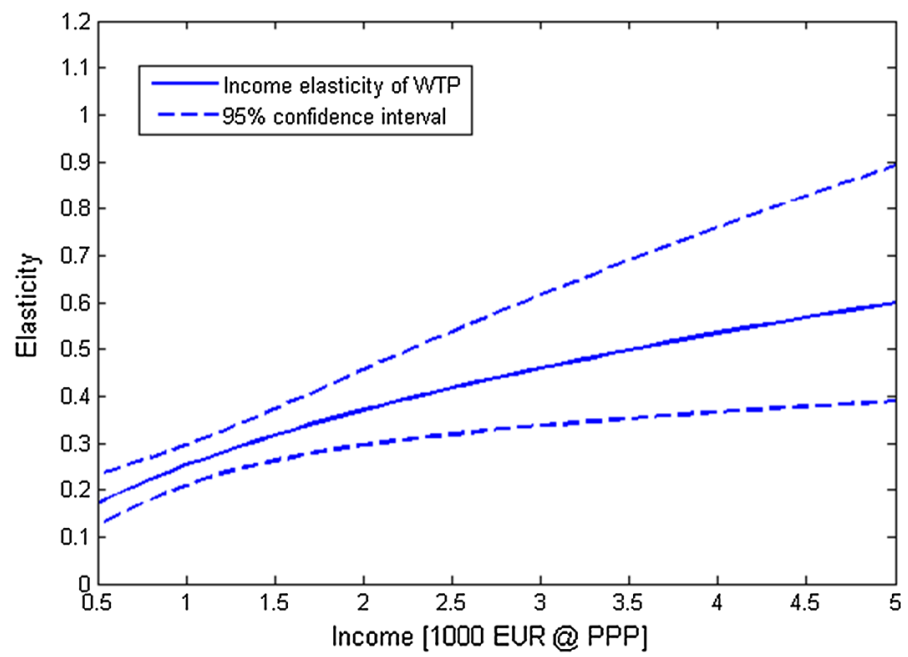

Fig. 5 Income elasticity of WTP-baseline model with controls and heteroskedascity

and Riera 1996), or that one can determine the magnitude of the income elasticity of the WTP for environmental improvement from such an "EKC" relationship.

Our empirical investigation of the relationship between WTP for eutrophication reduction and income was based on a large multi-country dataset for the Baltic Sea. This also leads to rejection of the null hypothesis that the elasticity of the WTP for pollution control with respect to income is constant. We find that this relationship is most likely to be concave, taking values of $0.1-0.2$ for low-income respondents and reaching values of $0.6-0.7$ for the highest income levels observed in our dataset.

The observation that the income elasticity of WTP is less than one is not new (Pearce 2006; Jacobsen and Hanley 2009). Although observed empirically from non-market valu- 
ation studies, this could be seen as difficult to reconcile with the evidence from national environmental expenditures and how these respond to changes in GNP. The share of environmental expenditure tends to rise with GNP (McFadden and Leonard 1993), and the elasticity of this relationship is typically above one (e.g., estimated at 1.2 for the European Union countries; Pearce and Palmer 2001). In this light, our finding of a non-constant income elasticity of WTP is reassuring - as noted by Haneman (1996), elasticities which are non-constant over ranges of income make it possible to reconcile the observed income elasticities of WTP below one with national expenditure elasticities greater than unity.

Our finding that the WTP for environmental improvement varies with respect to income is directly relevant to the growing interest in transferring environmental values estimated at one study site to other locations to aid environmental decision-making (Johnston and Rosenberger 2010; Johnston et al. 2015). Recommended guidance principles for transferring estimated WTP values for environmental improvement to other sites are often based on the assumption that the income elasticity of these WTP values must be constant (Ready and Navrud 2006; Czajkowski and Ščasný 2010; Lindhjem and Navrud 2015). In fact, such a "quick and easy" approach to benefit transfer can lead to very good performance in terms of lower transfer errors and minimum tolerance levels in comparison with even the very elaborate specifications (Bateman et al. 2011; Ahtiainen et al. 2015). Nonetheless, if this elasticity varies significantly with income levels, as our Baltic Sea case study application suggests, then assuming a constant elasticity may lead to significant errors in the WTP estimates based on such value transfers. Clearly, what is needed is robust estimation of a range of income elasticities of WTP for environmental improvement, as we have developed here. Also needed is a methodological framework which would allow one to incorporate these observed nonlinearities in the income elasticity of WTP to models predicting how WTP changes as respondents' income levels change.

Acknowledgements The authors are grateful for the financial support provided by four Finnish Ministries (Ministry of Agriculture and Forestry, Ministry of Environment, Ministry of Transport and Communications and Ministry of Finance), the Swedish Research Council for Environment, Agricultural Sciences and Spatial Planning (Formas); the Danish Strategic Research Council; the German Federal Environment Agency (UBA, Fkz 371025 202); and the Swedish Environmental Protection Agency. We would also like to thank the BalticSTERN Secretariat and team consisting of researchers from all the nine Baltic Sea states for joint work in data collection and the willingness to share the data. MC gratefully acknowledges the support of the Polish Ministry of Science and Higher Education and the Foundation for Polish Science. NH thanks MASTS for funding part of his work. We thank three referees for their comments on earlier versions of the paper.

Open Access This article is distributed under the terms of the Creative Commons Attribution 4.0 International License (http://creativecommons.org/licenses/by/4.0/), which permits unrestricted use, distribution, and reproduction in any medium, provided you give appropriate credit to the original author(s) and the source, provide a link to the Creative Commons license, and indicate if changes were made.

\section{References}

Ahtiainen H, Artell J, Czajkowski M, Hasler B, Hasselström L, Huhtala A, Meyerhoff J,Smart JCR,Söderqvist T, Alemu MH, Angeli D, Dahlbo K, Fleming-Lehtinen V, Hyytiäinen K,Karlõševa A, Khaleeva Y,Maar M, Martinsen L, Nõmmann T, Pakalniete K, Oskolokaite I,Semeniene D (2014) Benefits of meeting nutrient reduction targets for the Baltic Sea-a contingent valuation study in the nine coastal states. J Environ Econ Policy 3(3):1-28

Ahtiainen H, Artell J, Czajkows M,Meyerhoff J (2015) Performance of different approaches in international benefit transfer: insights from a nine country experiment. University of Warsaw, Department of Economics Working Paper no. 28/2015(176) 
Andreoni J, Levinson A (2001) The simple analytics of the environmental Kuznets curve. J Public Econ 80(2):269-286

Andrews DF, Gnanadesikan R, Warner JL (1971) Transformations of multivariate data. Biometrics 27(4):825840

Bateman IJ, Brouwer R, Ferrini S, Schaafsma M, Barton DN, Dubgaard A, Hasler B, Hime S, Liekens I, Navrud S, De Nocker L, Ščeponavičiūtė R, Seménienė D (2011) Making benefit transfers work: deriving and testing principles for value transfers for similar and dissimilar sites using a case study of the non-market benefits of water quality improvements across Europe. Environ Resour Econ 50(3):365-387

Bateman IJ, Carson RT, Day B, Hanemann MW, Hanley N, Hett T, Jones-Lee M, Loomes G, Mourato S, Özdemiroġlu E, Pearce DW, Sudgen R, Swanson J (2004) Economic valuation with stated preference techniques: a manual. Edward Elgar, Northampton

Berbeka K, Czajkowski M, Markowska A (2012) Municipal wastewater treatment in Poland—efficiency, costs and returns to scale. Water Sci Technol 66(2):394-401

Bessler DA, Weaver RD, Wohlgenant MK, Challant JA, King GA, Gallant AR (1984) Estimating functional forms with special reference to agriculture. Am J Agric Econ 66(2):204-224

Box GEP, Cox DR (1964) An analysis of transformations. J R Stat Soc Ser B (Methodological) 26(2):211-252

Carson RT, Hanemann WM (2005) Contingent valuation. In: Mäler KG, Vincent JR (eds) Handbook of environmental economics. Elsevier, Amsterdam

Champ PA, Boyle KJ, Brown TC (2004) A primer on nonmarket valuation. Kluwer Academic Publishers, Dordrecht

Czajkowski M, Ščasný M (2010) Study on benefit transfer in an international setting. How to improve welfare estimates in the case of the countries' income heterogeneity? Ecol Econ 69(12):2409-2416

Dillman DA, Smyth JD, Christian LM (2014) Internet, phone, mail, and mixed-mode surveys: the tailored design method, 4th edn. Wiley, New Jersey

Doksum KA, Wong C-W (1983) Statistical tests based on transformed data. J Am Stat Assoc 78(382):411-417

Ebert U (2003) Environmental goods and the distribution of income. Environ Resour Econ 25(4):435-459

Flores NE, Carson RT (1997) The relationship between the income elasticities of demand and willingness to pay. J Environ Econ Manag 33(3):287-295

Garlappi L, Skoulakis G (2011) Taylor series approximations to expected utility and optimal portfolio choice. Math Financ Econ 5(2):121-156

Ghalwash T (2008) Demand for environmental quality: an empirical analysis of consumer behavior in Sweden. Environ Resour Econ 41(1):71-87

Haneman MW (1996) Theory versus data in the contingent valuation debate. In: Bjornstad DJ, Kahn JR (eds) The contingent valuation of environmental resources: methodological issues and research needs. Edward Elgar, Cheltenham

Hökby S, Söderqvist T (2003) Elasticities of demand and willingness to pay for environmental services in Sweden. Environ Resour Econ 26(3):361-383

Horsch EJ, Lewis DJ (2009) The effects of aquatic invasive species on property values: evidence from a quasi-experiment. Land Econ 85(3):391-409

Israel D, Levinson A (2004) Willingness to pay for environmental quality: testable empirical implications of the growth and environment literature. B.E. J Econ Anal Policy 3(1):1-29

Jacobsen JB, Hanley N (2009) Are there income effects on global willingness to pay for biodiversity conservation? Environ Resour Econ 43(2):137-160

Johnston RJ, Rolfe J, Rosenberger R, Brouwer R (eds) (2015) Benefit transfer of environmental and resource values: a guide for researchers and practitioners. Springer, Dordrecht

Johnston RJ, Rosenberger RS (2010) Methods, trends and controversies in contemporary benefit transfer. J Econ Surv 24(3):479-510

Karaman S, Yavuz F (2014) Hedonic price analysis of the quality characteristics of the Anatolian hard red wheat. Agric Econ 60(10):469-478

Krinsky I, Robb AL (1986) On approximating the statistical properties of elasticities. Rev Econ Stat 68(4):715719

Kriström B, Riera P (1996) Is the income elasticity of environmental improvements less than one? Environ Resour Econ 7(1):45-55

Lindhjem H, Navrud S (2015) Reliability of meta-analytic benefit transfers of international value of statistical life estimates: tests and illustrations. In: Johnston RJ, Rolfe J, Rosenberger RS, Brouwer R (eds) Benefit transfer of environmental and resource values: a guide for researchers and practitioners. Springer, Dordrecht, pp 441-464

Lindhjem H, Tuan TH (2012) Valuation of species and nature conservation in Asia and Oceania: a metaanalysis. Environ Econ Policy Stud 14(1):1-22 
Manning W (2013) Dealing with skewed data on costs and expenditures. In: Jones AM (ed) The elgar companion to health economics. Edward Elgar Publishing, Cheltenham, pp 473-480

McConnell KE (1997) Income and the demand for environmental quality. Environ Dev Econ 2(04):383-399

McFadden D, Leonard GK (1993) Issues in the contingent valuation of environmental goods: methodologies for data collection and analysis. In: Hausman JA (ed) Contingent valuation: a critical assessment. North Holland Press, Amsterdam

Milon JW, Gressel J, Mulkey D (1984) Hedonic amenity valuation and functional form specification. Land Econ 60(4):378-387

Mishili FJ, Temu A, Fulton J, Lowenberg-DeBoer J (2011) Consumer preferences as drivers of the common bean trade in Tanzania: a marketing perspective. J Int Food Agribus Mark 23(2):110-127

Pearce D, Palmer C (2001) Public and private spending for environmental protection: a cross-country policy analysis. Fisc Stud 22(4):403-456

Pearce DW (2006) Framework for assessing the distribution of environmental quality. In: Serret Y, Johnstone $\mathrm{N}$ (eds) The distributional effects of environmental policy. Edward Elgar, Cheltenham, pp 23-78

Ready R, Navrud S (2006) International benefit transfer: methods and validity tests. Ecol Econ 60(2):429-434

Ready RC, Malzubris Jn, Senkane S (2002) The relationship between environmental values and income in a transition economy: surface water quality in Latvia. Environ Dev Econ 7(1):147-156

Roach B, Boyle KJ, Welsh MP (2002) Testing bid design effects in multiple bounded contingent valuation. Land Econ 78(1):121-131

Rowe RD, Schulze WD, Breffle WS (1996) A test for payment card biases. J Environ Econ Manag 31(2):178185

Sakia RM (1992) Box-cox transformation technique: a review. J R Stat Soc Ser D (Stat) 41(2):169-178

Stokey NL (1998) Are there limits to growth? Int Econ Rev 39(1):1-31

Zarembka P (1974) Transformation of variables in econometrics. In: Zarembka P (ed) Front Econ. Academic Press, New York, pp 81-104 